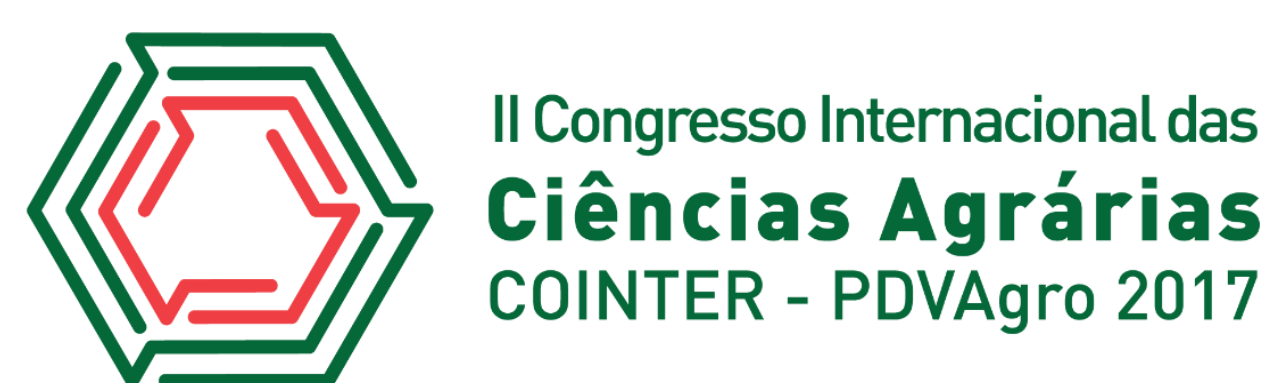

\title{
TOTAL DE FOLHAS POR PERFILHO DE CAPIM-CORRENTE EM FUNÇÃO DA ADUBAÇÃO FOSFATADA E NITROGENADA
}

Geovane Alves de Moura ${ }^{1}$; Guilherme Augusto dos Santos Sá ${ }^{2}$ Edvaldo Alves de Moura ${ }^{3}$; Fábio Junno Simões de Morais Bezerra ${ }^{4}$; Maurício Luiz de Mello Vieira Leite ${ }^{5}$

\section{Introdução}

O capim-corrente (Urochloa mosambicensis (Hanck.) Dandy) é uma das plantas forrageiras indicadas para o Semiárido do Brasil, devido a alta tolerância ao déficit hídrico e à temperaturas do ar elevadas, além de produzir elevada fitomassa, que pode ser consumida via pastejo ou estocada como feno ou silagem, para uso na alimentação de bovinos, caprinos, ovinos e outros (LEITE et al., 2017).

Segundo OLIVEIRA (1999), o capim-corrente requer para o seu pleno desenvolvimento, uma precipitação anual entre 500 e 1000 mm, sendo uma gramínea muito apreciada pelos animais, capaz de suportar pastejo próximo ao nível do solo e que aos poucos, vem ganhando espaço no Semiárido do Brasil.

É uma planta que possui variações no crescimento dependendo do tipo de solo, e clima na qual se encontra. Para SILVA et al. (1995), a fertilidade do solo intervém na quantidade de forragem produzida e na qualidade.

Esses aspectos reforçam a necessidade do conhecimento das características agronômicas do capim-corrente, pois são escassas as informações disponíveis na literatura sobre as características de crescimento dessa planta forrageira, principalmente nas condições do Semiárido brasileiro. Desse modo, objetivou-se avaliar o total de folhas por perfilho do capim-corrente, em função da adubação fosfatada e nitrogenada no Semiárido de Pernambuco.

\footnotetext{
${ }^{1}$ Bacharelado em Agronomia, UFRPE-UAST. geovane-am@ hotmail.com

${ }^{2}$ Bacharelado em Agronomia, UFRPE-UAST. gyllerme@ hotmail.com

${ }^{3}$ Bacharelado em Agronomia, UFRPE-UAST. edvaldo10am@hotmail.com

${ }^{4}$ Bacharelado em Zootecnia, UFRPE-UAST. fabio2014junno@ hotmail.com

${ }^{5}$ Professor Dr. Departamento de Agronomia, UFRPE-UAST. nopalea21@yahoo.com.br
} 


\section{Fundamentação teórica}

Dentre as estratégias de manejo que podem alavancar a produtividade de forragem e contribuir para a manutenção de elevados índices de produção animal, a aplicação de fertilizantes se destaca. $\mathrm{O}$ suprimento de nutrientes constitui-se importante fator na nutrição da planta forrageira, tendo em vista que a disponibilidade de nutrientes exerce grande influência na nutrição da planta, que reflete no desenvolvimento vegetal e na recuperação do capim (BONFIM-SILVA \& MONTEIRO, 2010).

Dentre os nutrientes considerados essenciais ao desenvolvimento das plantas, o nitrogênio é necessário, sobretudo, para a síntese de ácidos nucleicos, proteínas, hormônios, clorofila e vários outros compostos essenciais ao desenvolvimento das plantas, além de promover aumentos da produção de forragem (SILVEIRA \& MONTEIRO, 2007).

LOPES et al. (2011) observaram que a aplicação de doses crescentes de fósforo proporcionou aumento da taxa de acúmulo de MS do capim-xaraés durante o primeiro período seco pós estabelecimento da pastagem.

\section{Metodologia}

A pesquisa foi conduzida de 14 de outubro de 2014 a 08 de janeiro de 2015 , em condições de campo, na Universidade Federal Rural de Pernambuco (UFRPE), Unidade Acadêmica de Serra Talhada (UAST), localizada sob as coordenadas geográficas $07^{\circ} 57^{\prime} 01^{\prime}$ ', S e $38^{\circ} 17^{\prime} 53^{\prime \prime}$ O, altitude de 523 m, situada no município de Serra Talhada, Microrregião do Sertão do Pajeú, Mesorregião do Sertão Pernambucano, região de clima quente e seco.

A análise química do solo, coletado na UAST na profundidade de 0 a $20 \mathrm{~cm}$, foi realizada no Laboratório de Fertilidade dos Solos do Instituto Agronômico de Pernambuco (IPA) e revelou os seguintes teores de nutrientes: $\mathrm{pH}$ (água) $=6,80 ; \mathrm{P}($ extrator Mehlich I) $=$ $40,0 \mathrm{mg} \mathrm{dm}{ }^{-3} ; \mathrm{K}^{+}=0,45 \mathrm{cmol}_{\mathrm{c}} \mathrm{dm}^{-3} ; \mathrm{Ca}^{2+}=5,50 \mathrm{cmol}_{\mathrm{c}} \mathrm{dm}^{-3} ; \mathrm{Mg}^{2+}=1,6 \mathrm{cmol}_{\mathrm{c}} \mathrm{dm}^{-3} ; \mathrm{Al}=0,0$ $\mathrm{cmol}_{\mathrm{c}} \mathrm{dm}^{-3}$.

O solo, classificado como Luvissolo Crômico (EMBRAPA, 2013), utilizado no experimento, foi destorroado, submetido ao revolvimento para secagem ao ar, homogeneizado e acondicionado em vasos plásticos. Em cada vaso, com capacidade de 9,95 dm $\mathrm{dm}^{3}(22 \mathrm{~cm}$ de altura e $24 \mathrm{~cm}$ de diâmetro), disposto aleatoriamente sobre tijolos, colocou-se 7,2 $\mathrm{kg}$ de solo seco ao ar. Duas mudas de capim-corrente, obtidas na UAST, foram plantadas em cada vaso, 
em 14 de outubro de 2014. Para evitar condição de estresse hídrico, nos primeiros 10 dias, após implantação do experimento, todas as plantas foram mantidas em solo sob condições de capacidade de campo. Após 30 dias do plantio, todas as plantas foram submetidas ao corte de uniformização, a $10 \mathrm{~cm}$ do solo.

O total de folhas por perfilho do capim-corrente foi avaliado obedecendo ao delineamento experimental inteiramente casualizado, no esquema fatorial $2 \times 2$ (presença e ausência de nitrogênio x presença e ausência de fósforo), com quatro repetições.

As fontes de nitrogênio e fósforo utilizadas foram o sulfato de amônio com $20 \%$ de $\mathrm{N}$ e o superfosfato simples com $18 \%$ de $\mathrm{P}_{2} \mathrm{O}_{5}$ solúvel em água, respectivamente. Utilizou-se uma dose de nitrogênio equivalente a $100 \mathrm{~kg} \mathrm{ha}^{-1}$ de $\mathrm{N}$ e uma dose de fósforo equivalente a $150 \mathrm{~kg}$

$\mathrm{ha}^{-1}$ de $\mathrm{P}_{2} \mathrm{O}_{5}$. O nitrogênio e o fósforo foram aplicados em cobertura, imediatamente após o corte de uniformização (14/11/2014). Durante todo o período experimental, os vasos foram mantidos livres de plantas invasoras.

Para avaliação das características de crescimento do capim-corrente por ocasião da colheita, foi marcado um perfilho em cada uma das parcelas experimentais. As lâminas foliares foram classificadas, de acordo com o estádio de desenvolvimento, como folha em expansão (quando não havia exposição da lígula), e folha expandida (quando a lígula estivesse visível). Após essa classificação foi realizada a contagem das lâminas foliares presentes em cada perfilho.

Os dados foram submetidos à análise de variância para verificação da significância dos tratamentos por meio do Teste F, ao nível de $1 \%$ de probabilidade. Sendo F significativo, as médias dos tratamentos foram comparadas pelo teste de Tukey, ao nível de 5\% de probabilidade. Utilizou-se o programa estatístico R-project versão 2.13.1 for windows.

\section{Resultados e discussão}

Verifica-se na Tabela 1 que não houve efeito $(\mathrm{P}>0,01)$ da adubação para Total de Folhas por Perfilho (TFP) do capim-corrente. 
Tabela 1. Médias do total de folhas por perfilho (TFP) do capim-corrente, em função da presença ou ausência de nitrogênio e fósforo. Fonte: Própria

\begin{tabular}{ccc}
\hline $\begin{array}{c}\mathrm{N} \\
\left(\mathrm{kg} \mathrm{ha}^{-1}\right)\end{array}$ & $\begin{array}{c}\mathrm{P}_{2} \mathrm{O}_{5} \\
\left(\mathrm{~kg} \mathrm{ha}^{-1}\right)\end{array}$ & $\begin{array}{c}\text { TFP } \\
(\mathrm{un})\end{array}$ \\
\hline 0 & 0 & 7,00 \\
0 & 150 & 8,50 \\
100 & 0 & 8,00 \\
100 & 150 & 11,50 \\
\hline Média & & 8,75 \\
CV (\%) & & 37,90 \\
\hline
\end{tabular}

$\mathrm{N}=$ nitrogênio; $\mathrm{P}_{2} \mathrm{O}_{5}=$ fósforo. $\mathrm{CV}=$ coeficiente de variação.

O número total de folhas por perfilho é uma variável importante da planta, pois influencia diretamente a produção de matéria seca (MESQUITA \& NERES, 2008). Segundo SILVA et al. (2009), a adubação nitrogenada pouco influencia o número total de folhas por perfilho. Estes autores verificaram maior número total de folhas por perfilho com adubação de $157 \mathrm{mg} \mathrm{dm}^{-3}$ de $\mathrm{N}$.

O total de folhas por perfilhos (TFP) do capim-corrente não foi influenciado na presente pesquisa com a adubação fosfatada e nitrogenada devido ao curto período de avaliação, um ciclo de apenas 30 dias.

\section{Conclusão}

É necessário avaliar a influencia da adubação com nitrogênio e fósforo no total de folhas por perfilho do capim-corrente em um período superior a um ciclo de crescimento.

\section{Referências}

BONFIM-SILVA \& MONTEIRO, 2010. Nitrogênio e enxofre na adubação e em folhas diagnósticas e raízes do capim braquiária em degradação. Revista Brasileira de Zootecnia, v.39, n.8, p.1641-1649, 2010. 
EMBRAPA - Empresa Brasileira de Pesquisa Agropecuária - Centro Nacional de Pesquisa de Solos. Sistema Brasileiro de Classificação de Solos. 3. ed. Brasília: Embrapa Solos, 2013. $353 \mathrm{p}$.

LEITE, M. L. M. V.; LUCENA, L. R. R.; SÁ JUNIOR, E. H.; CRUZ, M. G. Estimativa da área foliar em Urochloa mosambicensis por dimensões lineares. Revista Agropecuária Técnica, v. 38, n. 1, p. 9-16, 2017.

LOPES, J.; EVANGELISTA, A. R.; PINTO, J. C.; QUEIROZ, D. S.; MUNIZ, J. A. Doses de fósforo no estabelecimento de capim-xaraés e estilosantes Mineirão em consórcio. Revista Brasileira de Zootecnia, v.40, n.12, p.2658-2665, 2011.

MESQUITA, E. E.; NERES, M. A. Morfogênese e composição bromatológica de cultivares de Panicum maximum em função da adubação nitrogenada. Revista Brasileira de Saúde e Produção Animal, v. 9, n. 2, p. 201-209, 2008.

OLIVEIRA, M. C. de. Capim urocloa: produção e manejo no semi-árido do Nordeste do Brasil. Petrolina, PE: (EMBRAPA-CPATSA. Circular Técnica, 43), 1999. 20 p

SILVA, C. C. F.; BONOMO, P.; PIRES, A. J. V.; MARANHÃO, C. M. A.; PATÊS, N. M. S.; SANTOS, L. C. Características morfogênicas e estruturais de duas espécies de braquiária adubadas com diferentes doses de nitrogênio. Revista Brasileira de Zootecnia, v. 38, n. 4, p. 657-661, 2009.

SILVA, C. M. M. S.; FARIA, C. M. B. Variação estacional de nutrientes e valor nutritivo em plantas forrageiras tropicais. Pesquisa Agropecuária Brasileira, Brasília, v.30, n.3, p. 413420, mar. 1995.

SILVEIRA, C. P.; MONTEIRO, F. A. Morfogênese e produção de biomassa do capimtanzânia adubado com nitrogênio e cálcio. Revista Brasileira de Zootecnia, v.36, n.2, p.335342, 2007. 